\title{
Sudaki Ultrases Hizının Sıcaklığa ve Tuzluluğa Bağlılığının İncelenmesi
}

\author{
Tuğba Özge ONUR \\ Bülent Ecevit Üniversitesi, Elektrik-Elektronik Mühendisliği Bölümü, 67100 Zonguldak, Türkiye
}

\begin{abstract}
ÖZET
Bu çalışmada, suda ultrases hızının tuzluluk ve sıcaklıkla değişimi incelenmiştir. Tuzlu su, kullanılan saf su hacminde ölçülen miktarda sofra tuzunun $(\mathrm{NaCl})$ çözdürülmesiyle hazırlanmıştır. Ölçümler plexi camları olan dikdörtgen bir havuzun içinde yapılmıştır. Boyuna ses ötesi darbeleri suya göndermek ve almak için $4 \mathrm{MHz}$ 'lik transdüser kullanılmıştır. Deneysel ölçümlerden elde edilen veriler kullanılarak hızı, sıcaklık ve tuzluluk fonksiyonu olarak tanımlayan matematiksel bir ifade geliştirilmiştir. Sonuçlar, ultrasonik hızın sıcaklık ve tuzlulukla arttığını göstermiştir.
\end{abstract}

Anahtar kelimeler: Ultrasonik hız, transdüser, sıcaklık etkisi, tuzluluk etkisi

\section{Investigating The Dependency of Ultrasonic Speed On Temperature and Salinity in Water}

\begin{abstract}
In this study, investigations of variations of ultrasonic speed with salinity and temperature in water samples are reported. Initially samples of saline water were prepared by dissolving measured quantities of salt (table salt, $\mathrm{NaCl}$ ) in a given volume of pure water. Measurements were carried out in a rectangular bath having plexi-glass windows. One transducer with $4 \mathrm{MHz}$ is used for launching and receiving the longitudinal ultrasonic pulses through the water. A mathematical expression describing speed as a function of temperature and salinity is developed. Results indicate that ultrasonic speed increases with temperature and salinity.
\end{abstract}

Keywords: Ultrasonic speed, transducer, temperature effect, salinity effect

\section{GIRIS}

$20 \mathrm{kHz}$ 'in üzerindeki sesler ultrases olarak adlandırılır [1]. Ses farklı ortamlarda farklı davranışlar göstererek yayılır. Sıvı karışımlarında ses hızı ses dalgalarının basınç genliğinin, frekansın, dış basıncın, karışımın bileşen konsantrasyonlarının ve sicaklığın bir fonksiyonudur. Ultrases uygulamalarında ses hızı, bir veya iki değişkene (sıcaklık, yoğunluk, konsantrasyon) bağlı olarak incelenir [2-5]. Günümüzde ultrases, endüstride, tıpta, elektronikte, savunma konularında ve malzeme karakterizasyonlarında oldukça geniş uygulama alanına sahiptir [6].

Malzeme karakterizasyonunda ultrases kullanılması ilk olarak Sokolov [7] tarafından gerçekleştirilmiştir. Ultrases ile malzeme karakterizasyonunun dalga hızı ve azalma (attenuation) ölçümleri ile gerçekleştirilmesi Mason ve McSkimmin [8] tarafından başlatılmıştır. Malzemelerin ultrasonik karakterizasyonu, dalganın hızındaki veya genliğindeki değişimlerin veya belirli bir ortama geçen dalganın frekans spektrumundaki değişimlerin ölçülmesini gerektirir. $\mathrm{Bu}$ parametreler ortama gönderilen darbelerin veya ortamdaki süreksizlik veya sinırlardan kaynaklanan geri dönen ekoların analiz edilmesiyle ölçülebilir.

Ultrasonik dalgalar kullanılarak malzeme kusurlarını karakterize etmek ve yerini belirleyebilmek için birçok çalışma yapılmıştır. Buna rağmen, malzeme karakterizasyonunun ultrason kullanılarak incelenebilen çok sayıda başka yönü vardır [9]. Ultrason kullanılarak deniz sularının tuz ve mineral bileşimlerinin miktarı belirlenebilir. Ultrasonik dalgaların hızının tuz bileşenine ve sıcaklığa göre değiștiği bilinmektedir [9]. Bu çalışmada, laboratuvarda hazırlanan tuzlu suda tuz ve sicaklık bileşeninin fonksiyonu olarak ses hızı incelenmiştir. Deneysel veri, ultrasonik hızı tuzluluk ve sicaklığın fonksiyonu olarak tanımlayan bir matematiksel ifade geliştirmek için kullanılmıştır. $\mathrm{Bu}$ bilgi, tatlı su altındaki kaynakların yerleştirilmesinde kullanılabileceği gibi herhangi bir su altı nesnesinin konumunun belirlenmesine de yardım eder. 


\section{SIVILARDA ULTRASES HIZ BAĞINTISI}

Ultrases, ortamda yayılan bir titreşim enerjisi olduğundan ultrases oluşturmak, yüksek frekanslı bir titreşim hareketi oluşturmaktır. Yüksek frekanslı bu titreşimleri meydana getiren ve algılayan elemanlara transdüser adı verilir. Piezoelektrik transdüserler elektrik enerjisini akustik enerjiye veya akustik enerjiyi elektrik enerjisine dönüştüren elemanlardır $[5,10]$.

Ultrasonik hız ölçümleri ile bir ortamın bazı özellikleri belirlenebilir. Eğer yoğunluk biliniyorsa ultrasonik hızlardan, sıvı maddeler için sıvının hacim esnekliği (Bulk) modülü ve akustik empedansı hesaplanabilir. Sıvılar içinde boyuna dalga ilerleyebildiğinden hız,

$$
v_{t}=\sqrt{\frac{E_{v}}{\rho}}
$$

şeklinde tanımlanabilir. Burada, $\mathrm{v}_{\mathrm{t}}(\mathrm{m} / \mathrm{s})$ boyuna dalga ses hızı, $E_{v}$ sıvının hacim esnekliği modülü ve $\rho(\mathrm{g} / \mathrm{l})$ yoğunluk olarak tanımlanır [5].

Elastikiyet, sıkışma ve gerilme sonrası ortamın kendi orjinal boyutuna geri dönme kabiliyeti olarak tanımlanabilir [11]. Sıvının hacim değişimine karşı gösterdiği direnç, $\mathrm{E}_{\mathrm{v}}$ hacim esneklik sabiti ile ölçülür. $\mathrm{E}_{\mathrm{v}}$, hacim esnekliği modülü basınçtaki $\Delta \mathrm{P}$ değişimin, hacimdeki kesirsel $(-\Delta \mathrm{V} / \mathrm{V})$ değişimine oranıdır [12].

$$
E_{v}=-\frac{-\Delta \mathrm{P}}{\Delta \mathrm{V} / \mathrm{V}}
$$

Sıvı ortamlarda yayılan ultrasonik dalgaların özelliklerinden dolayı şiddeti azalır. Dalga kaynağından x kadar uzaktaki bir noktada genlik,

$$
A=A_{0} e^{-\alpha x}
$$

şeklinde üstel olarak azalmaktadır. Eşitlik (3)'te, $A_{0}$ başlangıç genliği, $\mathrm{x}$ dalganın aldığı mesafe ve $\alpha$ ise ortamın emilim veya soğurma katsayısıdır.

\section{DENEY DÜZENEĞ'̇}

$4 \mathrm{MHz}$ 'lik piezoelektrik transdüser hem alıc1 hem verici olarak kullanılmaktadır. Çok kısa elektrik darbelerinin transdüsere uygulanmasıyla üretilen ultrasonik dalga, bir kuplaj ortamı vasıtasıyla hızın ölçüleceği ortama gönderilir. Dalga malzeme içinde ilerlerken aynı transdüser alıcı olarak çalışmaya başlar. Arka cidardan yansıyan ultrasonik dalga transdüsere ulaştığında mekanik titreşimler elektrik darbelerine dönüştürülür. Ancak, burada ultrasonik enerjinin çok az bir kısmı elektrik enerjisine dönüşür. Kalan kısmı transdüser ile malzeme parçası ara kesitinden yansıyarak ve tekrar aynı yolu alarak ikinci arka cidar yankısı (eko) olarak transdüsere ulaşır. $\mathrm{Bu}$ şekilde bir dizi ardışık arka cidar yankısı elde edilir. Şekil 1 'de sıvı içinde iletilen darbe ve oluşan yankılar gösterilmiştir. Örnek malzeme içinde yayılma mesafesinden ardışık yansıtılan darbeler arasındaki geçiş zamanının ölçülmesiyle ultrasonik dalganın yayılma hızı bulunabilir.
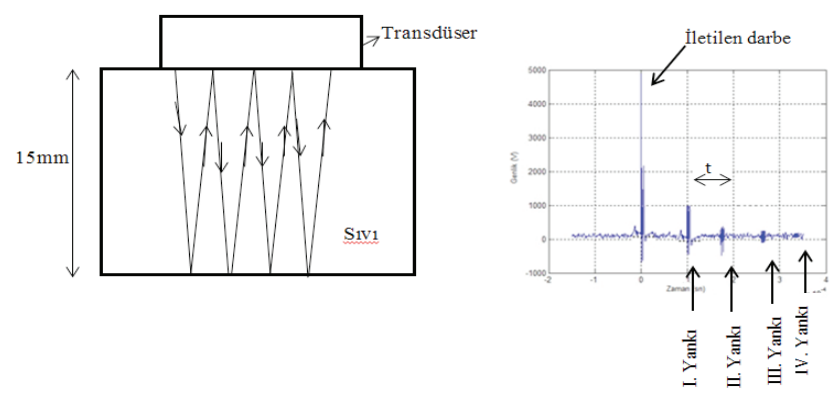

Şekil 1. Kullanılan sıvıda ilerleyen darbe ve yankılar.

Ultrasonik hız ölçümleri saf su ve tuzlu suda 4 MHz'lik 4.67 9.8 (çap $\times$ boy) $\mathrm{mm}$ boyutlu piezoelektrik transdüser (Badai, model TA0040104) kullanılarak yapıldı. Kullanılan deney düzeneği Şekil 2'de verilmiştir. Tuzlu su örneği, ölçülen miktardaki tuzun (sofra tuzu, $\mathrm{NaCl}$ ) belirli hacimdeki saf suda çözdürülmesiyle elde edilmiştir. Ölçümler, 15 mm sıvı ile doldurulan dikdörtgen plexi cam havuzun içinde yapılmıştır. Darbe-yankı yöntemi kullanılarak transdüserin boyuna ultrasonik darbeleri hem iletmesi hem de almasi sağlanmıştır. İletilen işaret, fonksiyon jeneratörü (Wavetek, Model 191) kullanılarak veri hızı $100 \mathrm{~Hz}$ olan 1 ms gecikmeli sinüzoidal işaret şeklinde üretilmiştir. Darbe genişliği $10 \mu \mathrm{s}$ ve frekans $10 \mathrm{MHz}$ olarak ayarlanmıştır. İletilen işaret $20 \mathrm{kHz}$ - $10 \mathrm{MHz}$ aralığında çalışan, $50 \mathrm{~dB}$ kazancı olan yükselteç (ENI, model 240L) kullanılarak yükseltilmiştir ve 100 MHz frekanslı (Agilent Technologies, model DSO5012A) dijital bir osiloskop tarafindan kaydedilerek bilgisayara gönderilmiştir. Transdüser alıcı ve verici olarak kullanıldığı için alıcı devreyi yüksek voltaj iletim darbesinden korumak amacıyla koruma devresi kullanılmıştır [13].

Şekil 2'de verilen deney düzeneği kullanılarak $20^{\circ} \mathrm{C}$ 'de 15 mm yüksekliğindeki saf su için ultrasonik hız,

$$
v=\frac{2 d}{t}
$$


eşitliği kullanılarak $1472.50 \mathrm{~m} / \mathrm{s}$ olarak ölçülmüştür. Ses hızının belirlenmesiyle elde edilen deneysel veri, ultrason hızının tuz bileșeni ve sıcaklığa bağlılığını fonksiyon olarak tanımlayan bir matematiksel ifade elde etmek için kullanılmıştır.

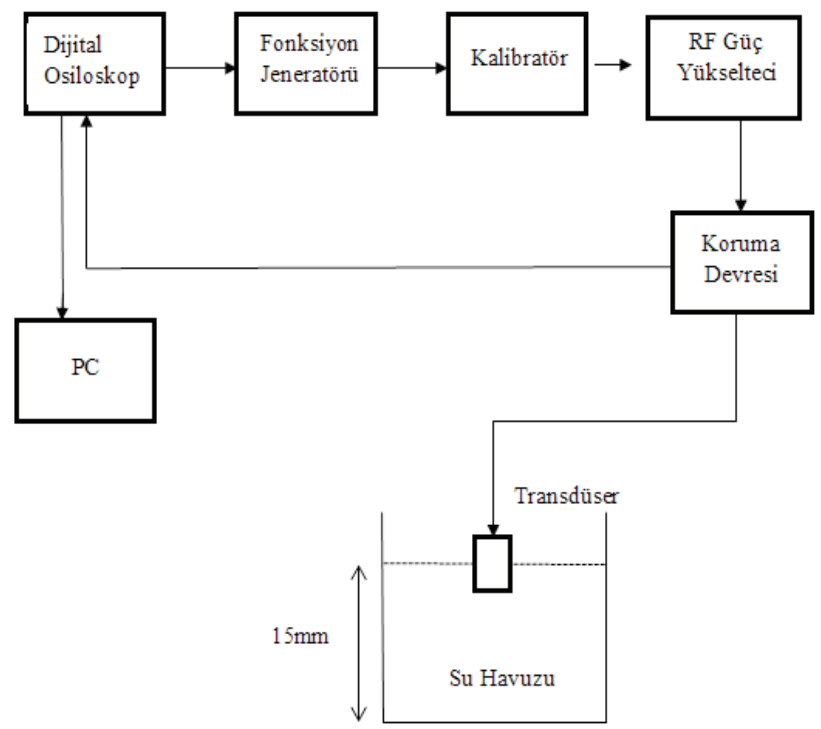

Şekil 2. Deney düzeneği.

\section{SAF SU VE TUZLU SUDA ULTRASONIKK HIZ ÖLÇÜMLERİ}

Ultrasonik hız, saf su içinde farklı sıcaklıklar için ölçülmüştür. Elde edilen değerler Tablo 1'de verilmiştir. Daha sonra, kullanılan saf suya sirasiyla $0,25,50,75,100$, 125,150 ve 200 gram sofra tuzu çözeltisi eklenerek ölçümler $20^{\circ} \mathrm{C}$ sabit sıcaklıkta tuzlu su çözeltisi için yapılmıştır. Tuz yoğunluğuna göre elde edilen ultrasonik hızlar Şekil 3'te gösterilmiștir.

Tuzlu su için elde edilen ultrasonik hız değerleri ve $20^{\circ} \mathrm{C}^{\prime} \mathrm{de}$ saf su için elde hız değeri kullanılarak tuz yoğunluğu ve hız arasındaki bağıntı (5) eşitliği ile ifade edilebilir,

$V(C)=0.94 C+1472.50$

Tuzlu suda ultrasonik hızın sicaklığa bağlılığının değerlendirilmesi için sırasıyla $10,20,30,40,50$ ve $60^{\circ} \mathrm{C}$ sıcaklıklarda farklı yoğunluktaki tuz miktarları ile ultrasonik hız ölçümleri yapılmıştır. Farklı yoğunluklarla, farklı sıcaklıklar için yapılan ölçümlerden elde edilen veriler Şekil 4 'te gösterilmiştir.
Tablo 1. 4 MHz'de Saf Suda Ultrasonik Hızlar.

\begin{tabular}{ll}
\hline Sicaklık $\left({ }^{\circ} \mathbf{C}\right)$ & Saf Su $\left(\mathrm{ms}^{-1}\right)$ \\
15 & 1454.60 \\
20 & 1472.50 \\
25 & 1486.50 \\
30 & 1497.80 \\
35 & 1507.50 \\
40 & 1515.80 \\
45 & 1523.10 \\
50 & 1529.07 \\
55 & 1535.07 \\
60 & 1541.10 \\
\hline
\end{tabular}

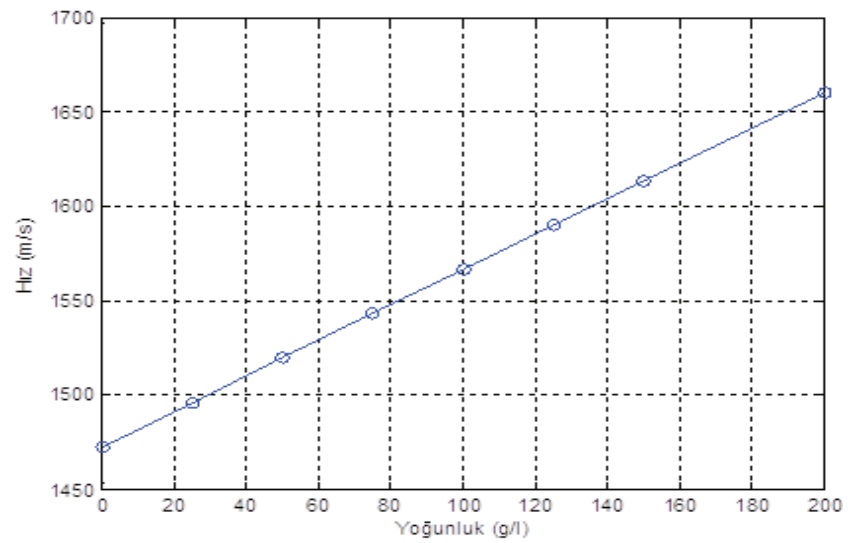

Șekil 3. Tuzlu su hız-yoğunluk grafiği.

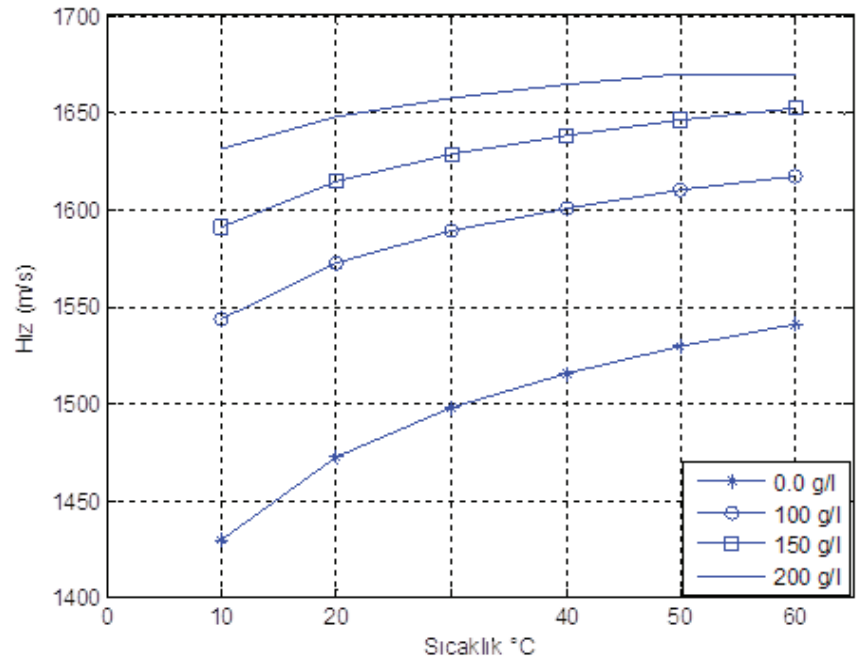

Şekil 4. Farklı yoğunluktaki tuz miktarı ve sıcaklığa göre elde edilen hiz verisi. 
Ölçümlerden elde edilen verilere göre farklı tuz yoğunlukları için yaklaşık değerleri veren hızın sıcaklığa bağlı matematiksel ifadeleri (6) - (9) eşitliklerinde verilmiştir,

$$
\begin{aligned}
& V(T)=62.4 \ln (T)+1285.6 \quad C=0 \mathrm{~g} / \mathrm{l} \\
& V(T)=41.7 \ln (T)+1449.5 \quad C=100 \mathrm{~g} / \mathrm{l} \\
& V(T)=35.3 \ln (T)+1515.4 \quad C=150 \mathrm{~g} / \mathrm{l} \\
& V(T)=26.7 \ln (T)+1581.1 \quad C=200 \mathrm{~g} / \mathrm{l}
\end{aligned}
$$

(6)-(9) eşitliklerinde $T$ sıcaklı̆̆,$V(T)$ ise sıcaklığa bağlı ultrasonik hızı ifade etmektedir. V hızı (10) eşitliği ile sıcaklık ve yoğunluk cinsinden ifade edilebilir,

$$
V(C, T)=S_{1}(C)+S_{2}(C) \ln (T)
$$

Burada $C$ yoğunluğu göstermekte olup $S_{1}(C)$ ve $S_{2}(C)$ sicaklık fonksiyonları,

$$
\begin{aligned}
& S_{1}(C)=1285.6+2.0105 C-0.0048 C^{2}+ \\
& 10^{-5} C^{3} \\
& S_{2}(C)=62.4-0.3322 C+0.0017 C^{2}- \\
& 5 \times 10^{-6} C^{3}
\end{aligned}
$$

şeklinde tanımlanır. Elde edilen sonuçların, daha önce saf suda ses hizını sıcaklık fonksiyonu olarak tanımlamak için 5. derece polinom kullanan Bilaniuk ve Wang [14] ve Dushaw ve arkadaşları [9] tarafından önerilen yöntemle uyumlu olduğu görülmektedir.

\section{TARTIŞMA VE SONUÇLAR}

Bu çalışmada sudaki ultrasonik hızın sıcaklığa ve tuzluluğa bağlılığını değerlendirmek için çeşitli ölçümler yapılarak matematiksel ifadeler geliştirilmiştir. $20^{\circ} \mathrm{C}$ 'deki saf suda ultrasonik hız 1472,50 m/s olarak ölçülmüştür. Ölçümlerden elde edilen sonuçların aynı sıcaklıkta Kroebel ve Mahr [15] tarafından elde edilen sonuçla yaklaşık olarak aynı olduğu görülmüştür.

Saf suda sıcaklık artırılarak ultrasonik hızların ölçülmesi için yapılan deneylerde (Tablo 1), her $5^{\circ} \mathrm{C}^{\prime}$ lik sıcaklık değeri artışında hız değerinin de arttığı ancak artan sıcaklık değerlerinde hız değerindeki artışın azaldığı görülmektedir. $20^{\circ} \mathrm{C}$ 'deki tuzlu su için yapılan ölçümlerde ise, hız değerinin tuz yoğunluğu ve sıcaklık artıkça arttığı görülmüştür. Ancak farklı tuz yoğunluklarındaki tuzlu sularda ultrasonik hız değerindeki artışın saf sudaki artıştan daha az olduğu tespit edilmiştir.

Ayrıca, bu çalışmada, ölçümlerden alınan veriler kullanılarak elde edilen matematiksel ifadeler ile belirli sicaklıktaki suların tuz veya mineral bileşimlerinin miktarı belirlenebilir. Yapılan çalışmalar geliştirilerek, su altı kaynaklarının yerleştirilmesinde ya da herhangi bir su altı nesnesinin konumunun belirlenmesinde kullanılabilir.

\section{KAYNAKÇA}

[1] Novelline, R. (1997). Squire's fundamentals of radiology (5. ed.). Harvard University bask1, s. 34-35.

[2] Dymling, S.D., Persson, H.V., Hertz T.G. ve Lindstrom K.A. (1991). A new ultrasonic method for fluid property measurements. Ultrasound in Medicine, Biology, 17, 497-500.

[3] Imano, K., Okuyama, D., Chubach, N. (1991). Technique of measuring sound velocity in liquid and solid materials. Electronic Letters, 27(17), 1562-1564.

[4] Eggers, F. (1992). Ultrasonic velocity and attenuation meaurements in liquids with resonators, extending the $\mathrm{MHz}$ frequency range. Acustica, 76(231).

[5] Donnel, M., Busse, L.J. ve Miller, J.G. (1981). Methods of experimental physics, Vol 19. Academic Press, New York, s. 29-65, 85-107.

[6] Peshkovsky, A.S., Peshkovsky, S.L. (2010). Acoustic cavitation theory and equipment design principles for industrial applications of high-intensity ultrasound. Book Series: Physics Research and Technology, NY: Nova Science Publishers, Hauppauge, New York.

[7] Sokolvo, S.Y. (1929) On the problem of the propagation of ultrasonic oscillations in various bodies. Elek. Nachr. Tech., 6, 454-460.

[8] Mason, W.P. ve McSkimm, H.J. (1947). Attenuation and scattering of high frequency sound waves in metals and glasses. Journal of the Acoustical Society of America, 19, 464 -473.

[9] Dushaw, B.D., Worcester, P.F., Cornuelle, B.D. ve Howe, B.M. (1993). On equation for the speed of sound in seawater. J. Acoust. Soc. Am., 93, 255-275.

[10] Medlock, R.S. (1983). Sensors for mechanical properties. J. Phys. E: Sci. Instrum., 16(10), 964-972.

[11] de With, G. (2006). Structure, deformation, and integrity of materials, volume I: fundamentals and elasticity. Wiley-VCH Verlag, Weinheim, Germay, s. 32.

[12] Kittel, C. (2005). Introduction to solid state physics. 8. ed., Weinheim: Wiley-VCH Verlag, Weinheim, 
Germany.

[13] Fuller, M.I., Blalock, T.N., Hossack J.A. ve Walker, W.F. (2007). Novel transmit protection scheme for ultrasound systems. IEEE Transactions on Ultrasonics, Ferroelectrics, and Frequency Control, 54(1), 79-86.

[14] Bilaniuk, N. ve Wong, G.S.K. (1993). Speed of sound in pure water as function of temperature. J. Acoust. Soc. Am., 93(3), 1609-1612.

[15] Kroebel, W., Mahr, K.H. (1976). Recent results of absolute sound velocity measurements in pure water and sea water at atmospheric pressure. Acustica, 35, 154-164. 